\title{
State of Art of Thin Film Photovoltic Cell: A Review
}

Rohan Vijay Salve

Government College of Engineering, NAGPUR, Maharashtra, India

\section{Article Info}

Volume 7, Issue 4

Page Number: 157-163

Publication Issue :

July-August-2020

\section{Article History}

Accepted : 01 July 2020

Published : 30 July 2020

\section{ABSTRACT}

The latest progress and future perspectives of thin-film photovoltaic technology are reviewed herein. This paper reviews the two thin-film solar cell technologies copper indium gallium selenide (CIGS), and cadmium telluride $(\mathrm{CdTe})$ and their parameter affecting them. Thin-film solar cell offers a variety of choices in term of device design, tunable property (lifetime, absorption length, conductivity) and verity substrate. Proper understanding of thin-film photovoltaic cells under various parameters like temperature, bandgap, conversion efficiency, open-circuit voltage, and short circuit current, fill factor, and thickness.

Keywords : Photovoltaic material and photovoltaic conversion efficiency and review index

\section{INTRODUCTION}

Electricity systems worldwide are changing. Global demand for, and dependence on electric- city is increasing and, as environmental concerns become more pressing, so does the focus on the reduction of greenhouse gas emissions. Due to four main requirements - high efficiency, low-cost production, high throughput, and high specific power, a major research and development focus has been shifted towards flexible solar cells.

This is resulting in a move towards renewable technology such as photovoltaic technology. Basically current scenario two types of photovoltaic technology use first is silicon wafer base technology and second is thin-film photovoltaic technology. In thin-film photovoltaic technology cell, the material property is tunable just like optical property and electrical property can be controlled during deposition. A solar cell is a junction device obtained by placing two electronically dissimilar materials together with a thin film electronic barrier in between to separate charge and device must ensure a high conversion efficiency of solar photon and high collective efficiency of excited charge carrier.

Thin-film it is a random nucleation and growth process of individually condensing/ reacting, atomic and ionic molecular species on a substrate. The structural chemical, physical strongly depend on the deposition parameter of the film. The thickness of the thin film Nano-meter to several 10s of a micrometer. 
Thin-film basically films deposition technique in which substrate can be flexible as well as rigid it mainly depends upon the requirement. Ideally, the absorber material of solar cells should be direct band dap semiconductor (1 to $1.5 \mathrm{eV}$ ) with a high solar optical absorption coefficient 104 to 106, and also recombination rate generated change carrier should below. The optimum thickness of an absorber in a solar cell is of the order of the inverse of the optical absorption coefficient.

\section{Why thin film use over thick film?}

- Low material consumption film thickness 1 to 5 $\mu \mathrm{m}$ ( wafer base solar cell 200-300 $\mu \mathrm{m}$ thick)

- Shorter energy payback period $<1$ year

- Monolithic integration

- Larger area module: cost advantage

- Tunable material property: optical and electrical properties, bandgap, many layer thickness and materials

- Surfaced can be modified to achieve the desired optical reflectance/transmission property and optical trapping effect.

- Different type of electronic junction single and tandem junction are feasible

\section{Thin-film solar cell device}

In thin-film photovoltaic technology different types of structure can be from just like homo-junction, metro-junction, and multiple-junction and $\mathrm{p}-\mathrm{i}-\mathrm{n}$ junction solar cells. The material composition ratio change as per we need the property to acquire higher efficiency and that case minimizing transmission losses and thermal losses. Thin-film photovoltaic cells are direct bandgap semiconductors that are way we requiring thinner material CIGS( $1.1 \mathrm{eV})$ and $\mathrm{CdTe}(1.42)$. During converting photon energy into electrical energy from thermal losses 33\% and transmission losses are $23 \%$ hence we can find optimum efficiency $44 \%$ and the efficiency can be reached $68 \%$ by using a number of a junction.

\section{Thin-film solar cell absorber material review and cell structure}

\subsection{Material}

\section{Cadmium telluride (CdTe) -}

Cadmium telluride solar cells are formed from cadmium and tellurium. Because of its ideal bandgap of $1.5 \mathrm{eV}$ and longer stability.

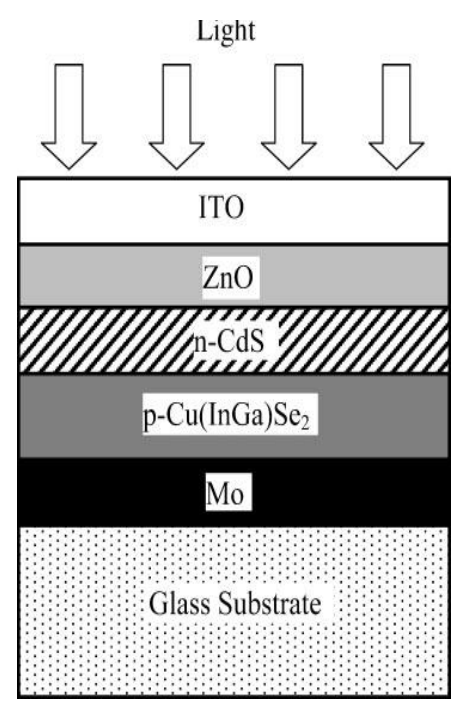

(a)

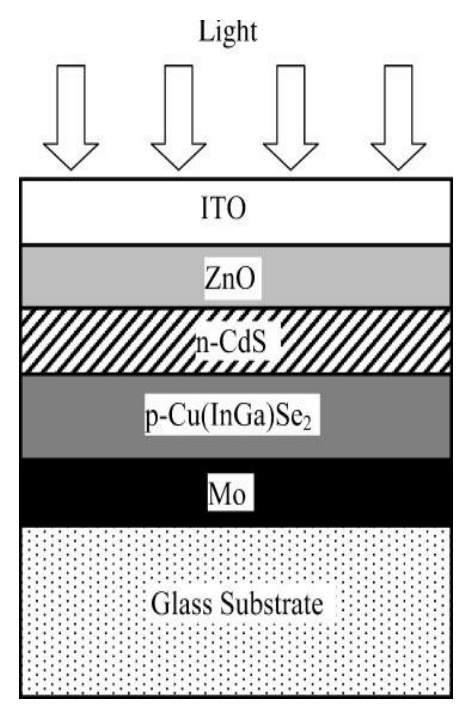

(b) 


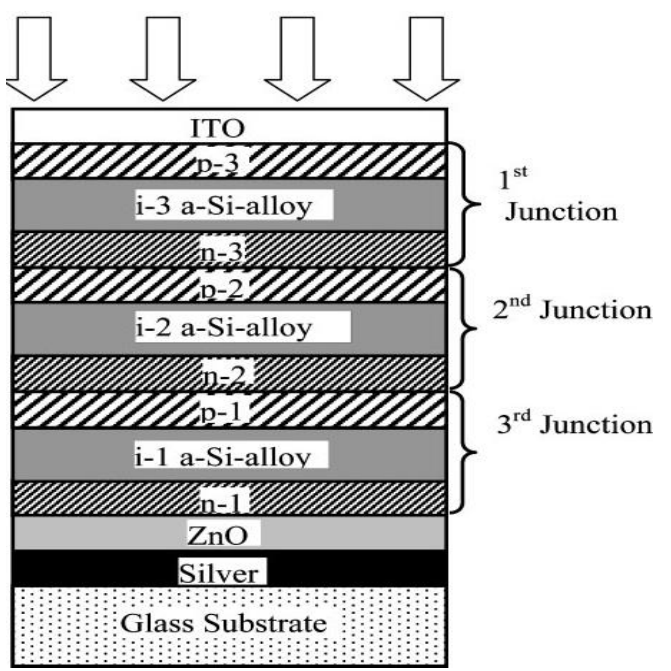

(c)

Figure 1. Thin-film structure for a hetero-junction and multi-junction [1]

CdTe is an ideal absorber material for high efficiency and having an absorption coefficient $10 * 5 / \mathrm{cm}$ in the visible region it sufficiently absorbed $90 \%$ incident photon. CdTe emerges as an ideal semiconducting material to sustain at high processing temperatures. The close-spaced sublimation (CSS) technique is used to deposit CdTe films to obtain large grains and a high growth rate. By using polymer and steel foil CdTe efficiency of solar cell reported $13.8 \%$ and 10.9\%[9].on flexible window glass substrate achieve 16.4\% efficiency[1]. The new world record of CdTe solar cells by using rigid glass achieved 22.1\% efficiency[10] but in the small areas compared with the theoretical maximum 29\% efficiency[1].

Copper indium gallium diselenide (CIGS) -

CIGS semiconductor has a direct band-gap. Its bandgap is a function of Gallium content which can be varied from $1.0 \mathrm{eV}$ to $1.72 \mathrm{eV}$ [11] that would result in the variation of other parameters of the solar cell. It is one of the most absorbing semiconductor materials (absorption coefficient of (3-6x105/cm) and also makes an excellent junction and a solar cell. The best efficiency of CIGS cells was $11.4 \%$ and about $13 \%$ for the module. Power has reported the highest cell efficiency of $18.8 \%$ [2]. The CIGS layer can be either crystallized in a single step during growth with sufficient chalcogen vapor pressure (co-evaporation) or formed by depositing a precursor film (typically a metal stack), which is then reacted by annealing in a sulfur/selenium environment[3].

\subsection{Substrate}

In the thin-film Photovoltaic cell, two types of arrangement can be formed first is a substrate (flexible) and the second is superstrate (rigid as well as flexible). A substrate is a supporting device and opaque, transparent. Flexible substrates should have high thermal stability, thermal expansion co-efficient matching with CIGS for good adhesion, excellent dielectric properties, and no impurity diffusion from substrates. Generally in thin-film technology, we use superstrate it gives better performance because of the interdiffusion of Cds during high-temperature CIGS growth.

\subsubsection{Polyimide substrate}

Which are attractive due to their lightweight, and highly flexible nature, no metallic impurities, suitable for metallic integration, suffer primarily from poor high-temperature stability which limits fabrication temperature to around $450^{\circ} \mathrm{C}$. Lowtemperature fabrication recipes have been attempted for many years but efficiencies have lagged and remained below 15\% [12]. The efficiency record for polyimide is $20.4 \%$, obtained by using a lowtemperature three-stage deposition process followed by sodium fluoride $(\mathrm{NaF})$ and potassium fluoride $(\mathrm{KF})$ post-deposition treatment [8]. One of the biggest issues with polymer foils is the high water vapor transmission rate and gas permeation of about 1 $\mathrm{g} / \mathrm{m} 2 /$ day. 


\subsubsection{Glass substrate}

It is low contamination and roughness as compared to polymer foil. Flexible glass is compatible with hightemperature processing and possesses high optical transparency which enables more photons to reach the absorber. The $\mathrm{Na}$ in the soda-lime glass substrate has been considered as a key prerequisite for efficient CIGS device fabrication. $\mathrm{Na}$ diffuses from the substrate into CIGS absorber and improves the grain growth and cell performance.[6].The most important factor in the case of glass substrate where the cell is protected on both sides by a very low water vapor transmission rate of $\sim 10-12 \mathrm{~g} / \mathrm{m} 2 /$ day. The ultra-thin $(\sim 100 \mu \mathrm{m})$ glass solves these issues; its transparency is the same as the rigid glass. It has an excellent encapsulation property with ultra-low WVTR which is not possible to achieve with metal and plastic foils. However, the cost of ultra-thin flexible glass is high but the problem in flexible glass substrates is bendable, they are not rolling able and they are restricted to the extent of bending.[3]

\subsubsection{Stainless steel foils substrate}

Flexible substrate stainless steel films are suitable for roll-to-roll deposition enabling a compact deposition system design as well as flexibility. The thermal expansion coefficient of stainless steel matches with that of CIGS film [3]. The conductivity of SS or other metallic substrates creates an additional challenge for the monolithic integration of multiple cells on a single substrate. For monolithic integration, flexible substrates should have insulating property or an insulating layer must be added between the substrate and cell Mo back contact in order to allow isolation between cells. This layer often serves a dual purpose as the diffusion barrier for impurities.

\subsection{Transparent conducting oxide (TCO)}

Transparent conducting oxides in general are n-type degenerate semiconductors with good electrical conductivity and high transparency in the visible spectrum.TCO use as an electrode/metallic contact and front contact as well as back contact in thin-film solar cells. The conductivity of a TCO depends on carrier concentration and mobility. Material like InSnO2 (ITO), $\mathrm{ZnO}$ is used as a TCO. The top of the electrode should allow more than $80 \%$ light to go in the cell. The resistivity of the thin film in the range of 105 to 1010 Ohm-cm metal contact should be continuous. Fluorine-doped tin oxide (FTO) and indium-doped tin oxide (ITO) are preferred front contact choices all over the world [4]. TCO also use as a light-trapping, anti-reflective coating hence they satisfy an equation continuous. Fluorine-doped tin oxide (FTO) and indium-doped tin oxide (ITO) are preferred front contact choices all over the world [4]. TCO also use as a light-trapping, anti-reflective coating hence they satisfy an equation.

$$
\text { Thickness of TCO }=[\lambda] /[4 n]
$$

$\lambda$ is wavelength of the photon. $\mathrm{n}$ is a refractive index.

\begin{tabular}{|c|c|c|c|c|c|}
\hline Property & Requirement & ITO & $\mathrm{SnO}_{2}: \mathrm{F}$ & ZnO:B & $\mathrm{ZnO}: \mathrm{AI}$ \\
\hline Transmission & $>90 \%$ & $95 \%$ & $90 \%$ & $90 \%$ & $90-95 \%$ \\
\hline Band sap & $>3.5$ & 3.7 & 4.3 & 3.4 & -3.45 \\
\hline $\begin{array}{l}\text { Refractive } \\
\text { index }\end{array}$ & -2 & $\sim 2$ & $\sim 2$ & -2 & $\sim 2$ \\
\hline $\begin{array}{l}\text { Sheet } \\
\text { resistance } \\
{[\Omega /]}\end{array}$ & $<10$ & $3-5$ & $6-15$ & $6-15$ & $4-15$ \\
\hline $\begin{array}{l}\text { Plasma } \\
\text { durability }\end{array}$ & resistant & low & good & excellent & excellent \\
\hline
\end{tabular}

Table show various type of TCO

\section{FACTOR AFFECTING SOLAR CELL PERFORMANCE}

\subsection{Effect of spectral content change}

Spectral content at a location can change various hours and various seasons. Thin-film solar cells performed better at lower light intensities due to 
smaller resistance losses. As you have seen low energy photo this module is low efficient work because the bandgap is high.

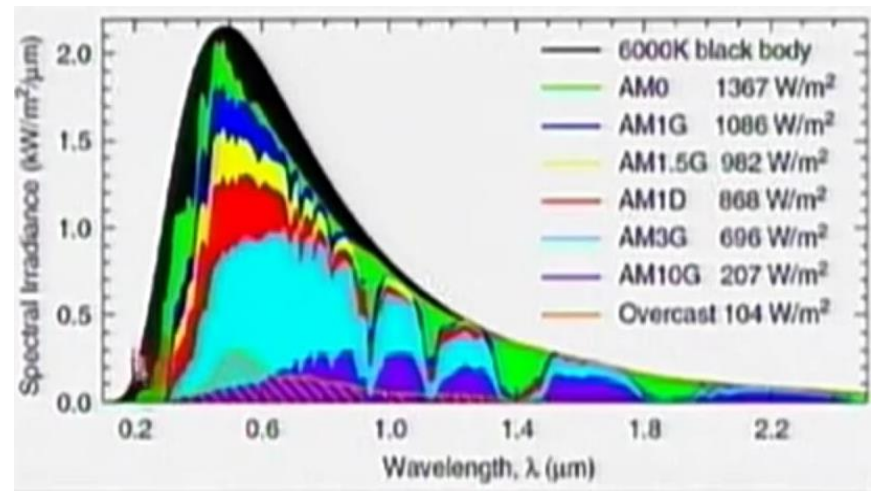

Fig 2 variation spectral radiation

The contribution due to spectrum when light intensity is low that time high energy photon $\%$ is also low hence it affected the performance of the solar cell. The energy required to the cell is always $\mathrm{Eg} \geq \mathrm{hv}$ then adversity affected the performance of the high bandgap material. The solar cell performs under standard operating conditions assuming they give the highest efficiency at that point $1000 \mathrm{w} / \mathrm{m} 2$, AM 1.5.

\subsection{Impact of cell performance by variation thickness $50 \mathrm{~nm}$ to $3 \mu \mathrm{m}$ for both CdTe and CIGS}

This test performance and analysis of thin-film singlejunction photovoltaic cell and we concluding point short circuit current and open-circuit voltage, efficiency at variation thickness shown by the graph.

\subsubsection{Short circuit current density -}

For CIGS and CdTe cell, it increases sharply till 200 $\mathrm{nm}$ and then increases slowly and after $1 \mu \mathrm{m}$, it becomes almost constant till $3 \mu \mathrm{m}$. JSC increases till $400 \mathrm{~nm}$ but decreases rapidly after that whereas, for CdTe cell, it increases till $400 \mathrm{~nm}$, and then it remains almost constant till [5].

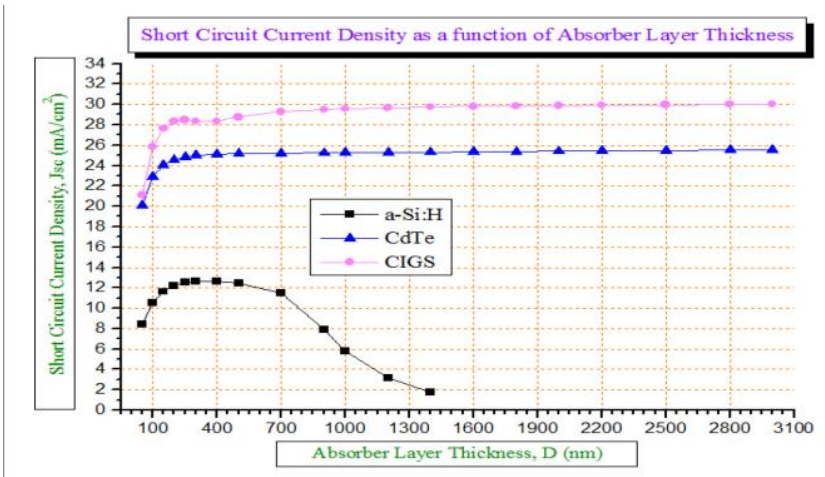

\subsection{2 open-circuit voltage}

CdTe cell provides stabilized VOC of $\sim 0.942 \mathrm{~V}$. CIGS cell reflects A sharp increase in VOC for absorber layer thickness ranging from $50 \mathrm{~nm}$ to $500 \mathrm{~nm}$. After $500 \mathrm{~nm}$, VOC increases very slowly till $3 \mu \mathrm{m}$.

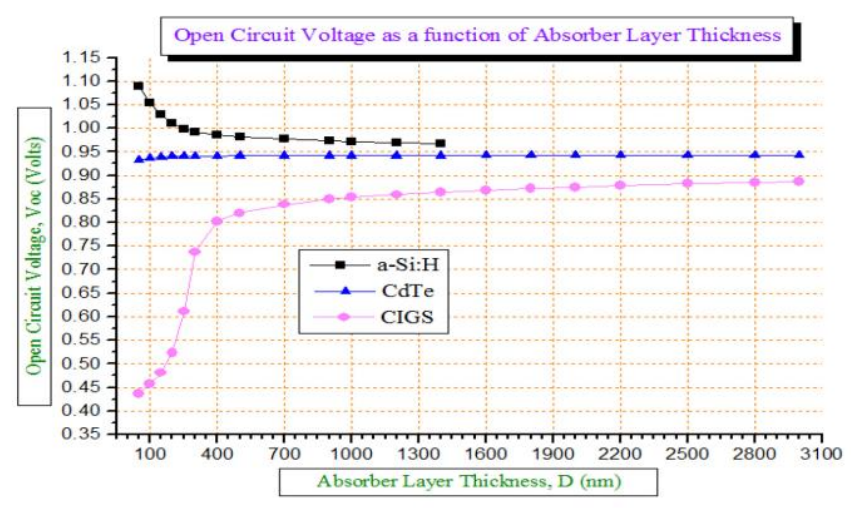

Fig 3. Voc Vs. Absorption thickness [5]

\subsubsection{Cell Efficiency, $\eta$}

For CdTe cell, it increases fast till $400 \mathrm{~nm}$ and from $700 \mathrm{~nm}$ to $3 \mu \mathrm{m}$ it remains almost constant. For CIGS cells, it increases rapidly to $700 \mathrm{~nm}$ and then increases gradually to $3 \mu \mathrm{m}$. It is clear that CdTe cell has highly stabilized efficiency with respect to an absorber layer thickness variation. 


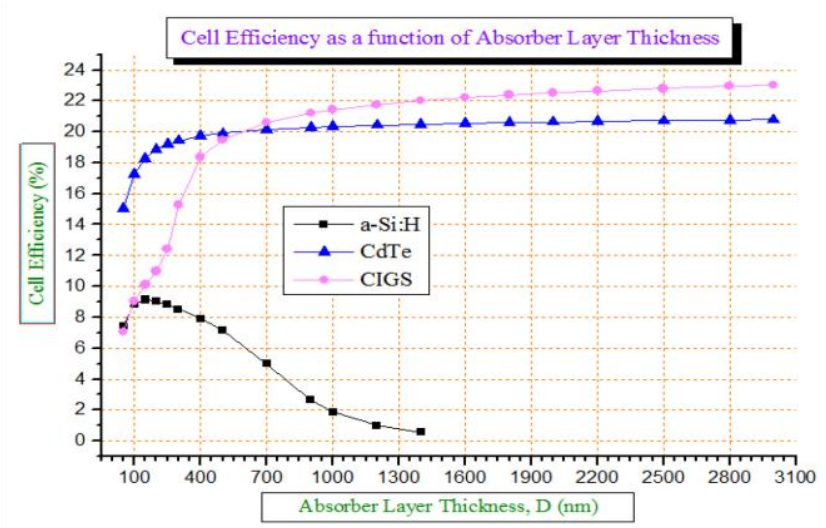

Fig 4. Efficiency Vs. Absorption thickness [5]

\subsubsection{Final outlook -}

We can conclude the impact of thickness at maximum efficiency achieved we propose $1 \mu \mathrm{m}(1000 \mathrm{~nm})$ thick CdTe absorber layer having efficiency of $20.342 \%$ $(\mathrm{VOC}=0.942 \mathrm{~V}, \mathrm{JSC}=25.255 \mathrm{~mA} / \mathrm{cm} 2, \mathrm{FF}=85.5 \%)$, $1 \mu \mathrm{m}$ thick CIGS absorber layer having efficiency of $21.44 \%(\mathrm{VOC}=0.853 \mathrm{~V}, \mathrm{JSC}=29.567 \mathrm{~mA} / \mathrm{cm} 2, \mathrm{FF}=$ $85.1 \%)$ at standard test condition.[5]

\subsection{Effect cell performance by variation cell temperature.}

All the parameters are a function of temperature. When the temperature increasing the short circuit current increasing very small but in case of opencircuit, the voltage decreases logarithmically and increasing a temperature more electro hole pair generated that way producing more recombination hence the efficiency of the cell decreeing and fill factor also decreasing

\section{CONCLUSION}

The extensive literature survey has been carried out for investing in the effect of thickness, temperature, and spectral content on thin-film photovoltaic cells. The literature survey has provided information and guidelines for the future prospects of thin-film cells.
The paper mainly focuses on presenting are view on the technological development of the thin-film cell.CdTe solar cell efficiency has shown a healthy increase in the past few years most visibly with record 23.03\% efficiency under standard operating conditions (AM1.5 and 1000watt/m2).

Thin-film cells offer the possibility of reducing the active material significantly that way a number of semiconductors are well suited in thin-film form for reasonably efficient solar cell devices to be manufactured on a large scale. In thin-film cell various type material use and their parameter changing we can be aching maximum record $44 \%$ efficiency. Thus, CdTe/CdS PV technology still needs a lot of research over a wide range of issues, ranging from further understanding of basic properties of the constituent materials to the advanced production technologies and the possible market perspective. To tackle all of these problems effectively, a long-term vision for photovoltaic and research are needed. Based on the review presented in this article, it is still believed that $\mathrm{CdTe} / \mathrm{CdS}$ solar cells will be a crucial candidate for the global low-cost solar cell market in the future.

\section{REFERENCES}

[1]. Progress in photovoltaics: research and applications prog. Photovoltaic: res. Appl. (2004)

[2]. Energy Exploration \& Exploitation, Mehreen Gul,1 Yash Kotak1, and Tariq Muneer2. (2016)

[3]. Ramanujam, J., Bishop, D.M., Todorov, T.K., Gunawan, O., Rath, J., Nekovei, R., Artegiani, E., Romeo, A., Flexible CIGS, CdTe and a-Si: H based thin-film solar cells: A review, Progress in Materials Science (2019)

[4]. A review of the improvement in the performance of CdTe/CdS thin-film solar cells through optimization of structural parameters 
Tarkeshwar Sinha1, Devjyoti Lilhare1, and Ayush Khare J Mater Sci (2019).

[5]. Comparative Study of the Second Generation aSi: H, CdTe, and CIGSThin-Film Solar Cells, Mahabub Alam Moon1, a*, Md. Ferdous Rahman1,b, Jaker Hossain2,c, and Abu Bakar Md. Ismail2,d Trans Tech Publications Ltd, Switzerland (2019)

[6]. Bodega ${ }^{\circ}$ rd M, Stolt L, Hedstro"m J. The influence of sodium on the grain boundary of CuInSe2 films for photovoltaic application. Proceedings of the 12th European Photovoltaic Solar Energy Conference (1994)

[7]. Brémaud, D. J. L. Investigation and Development of CIGS Solar Cells on Flexible Substrates and with Alternative Electrical Back Contacts. Ph.D. thesis, (2009)

[8]. Chirilă, A. et al. Potassium-induced surface modification of $\mathrm{Cu}(\mathrm{In}, \mathrm{Ga}) \mathrm{Se} 2$ thin films for high-efficiency solar cells. Nat. Mater. 12, 11071111 (2013)

[9]. EMPA Thin Films and Photovoltaics, March (2015)

[10].He S, Lu H, Li B, Zhang J, Zeng G, Wu L, Li W, Wang W, Feng L Study of CdTe/ZnTe composite absorbing layer deposited by pulsed laser deposition for CdS/CdTe solar cell. Mater Sci Semicond Process 67:41-45 (2017)

[11].H. Ullah, B. Marí, H. N. Cui, Investigation on the effect of Gallium on the efficiency of CIGS solar cells through dedicated software, Applied Mechanics and Materials, (2014)

[12].Chirila, A. et al. Highly efficient $\mathrm{Cu}(\mathrm{InGa}) \mathrm{Se} 2$ solar cells grown on flexible polymer films. Nat. Mater. 10, 857-861 (2011)

[13].Kessler, F. \& Rudmann, D. Technological aspects of flexible CIGS solar cells and modules. Sol. Energy, 77, 685-695 (2004).

\section{Cite this article as :}

Rohan Vijay Salve, "State of Art of Thin Film Photovoltic Cell: A Review", International Journal of Scientific Research in Science and Technology (IJSRST), Online ISSN : 2395-602X, Print ISSN : 23956011, Volume 7 Issue 4, pp. 157-163, July-August 2020 . Available

doi : https://doi.org/10.32628/IJSRST207382

Journal URL : http://ijsrst.com/IJSRST207382 